\title{
30 WHAT DO WE MEAN BY INFORMATION TECHNOLOGY? PERSPECTIVES ON STUDYING COMPUTING
}

\author{
Steve Sawyer \\ School of Information Sciences and Technology \\ The Pennsylvania State University \\ U.S.A. \\ Steven Haynes \\ School of Information Sciences and Technology \\ The Pennsylvania State University \\ U.S.A. \\ Duane Truex \\ Robinson College of Business \\ Georgia State University \\ U.S.A. \\ Ojelanki Ngwenyama \\ School of Business \\ Virginia Commonwealth University \\ U.S.A.
}

\section{INTRODUCTION}

The current information systems (IS) literature is embracing an increasingly explicit focus on organizational actions and issues relative to the design, construction, and use of IS. However, the socio-technical nature of the issues in IS suggests that this research should also inform those who build computing artifacts. For example, and as we do in this panel, both Morrison and George (1995) and Markus (2000) argue that IS research should be both more connected to, and say more about, the information technologies (IT) that are embedded in the systems being studied.

Stated more broadly, what is it about IS that IS researchers study? What can IS researchers say about information technologies that are a central part of their research? This panel contributes to the debate about the definition of IT 
research in three ways. First, we present a taxonomy of research on IT. Second, panelists provide a range of critical analyses on how IS research contributes to IT knowledge. Third, we provide a set of tangible recommendations for how IS researchers might add value through more informed forms of research about what it means to study IS and the IT embedded in them.

We begin by framing the discussions of the panelists with a five-part IT research taxonomy in which levels of analysis are contrasted with the ways in which IT are characterized (Sawyer 2000). Embedded in this taxonomy are issues with how IT is represented, how people (and their behaviors) are represented, and the kinds of question, methods, and insights that the various approaches can provide. This taxonomy is used to frame three different perspectives on studying IT, as follows.

\section{THE NATURE OF EXPLANATION IN INFORMATION SYSTEMS RESEARCH}

Explanation is one perspective on the role of IS research relative to IT. The range spanned by theories of explanation is bounded by extremes. For example, while Hempel and Oppenheim (1948) allowed that the criteria for what qualifies as a law could be relaxed to include probabilistic information, or even welltested empirical generalizations, the intent of this theory is clearly reductionist. At the other extreme is van Fraassen's (1980) pragmatic theory of explanation, which claims that explanation can only be understood in terms of the context in which it was requested. Somewhere between these two are functional theories of explanation, which are teleological in the sense that an entity or event is explained by reference to the reasons by which it came to occur or to exist (i.e., Cummins 1975).

\section{INTEGRATING IMPROVEMENT AND EXPLANATION RESEARCH IN INFORMATION SYSTEMS}

Another perspective on what it means to study IT and IS is to distinguish between improvement and explanation research (Vaishnavi 2000). Improvement research in IS/IT is oriented to improving the performance and effectiveness of artifacts. Improvement research has also been called prescriptive research, design research, or developmental research. Explanation research (also called descriptive research) is focused on understanding and explaining phenomena associated with information systems and technology. One interesting, and perhaps on the surface, paradox is that where many might see the more technical 
or improvement research as being wholly in the empirical and positivist camp, there are a range of theory building as well as theory testing approaches from both the intensive research as well as quantitative schools of thought.

\section{THE POVERTY OF INFORMATION TECHNOLOGY IN INFORMATION SYSTEMS RESEARCH}

A third perspective is to view the IS as a black box and, instead, focus on either people's interactions with the IS or their perceptions and decisions about the IS. Given the increasingly intimate relationships between people, their work, organization, and IT, it is no longer possible to separate the organizational process from the IS (e.g., Bostrom and Heinen 1978a, 1978b). For example how do you separate the organizational processes from a workflow management system? When this IT is used, the organizational processes and procedures become inscribed in the system (Ngwenyama and Lyytinen 1997).

To inquire into IS without opening the "black box" is like trying to study a planet by focusing solely on its atmosphere. So how is it that the IS field would fall into the trap of only studying the atmosphere of IS? Instead, and increasingly, a range of social theories (and theorists) have shown that the social structure of the organization, its norms, systems, and resources, become so embedded in the IS that they mediate (that is, determine the potential for action and its parameters) organizational actions (Monteiro and Hanseth 1996; Orlikowski 1992; Orlikowski and Tyre 1996; Vidgen and McMaster 1996). This orientation suggests that it is critical that IS research engage the roles, characteristics, and potential of the IT in the IS being studied.

\section{REFERENCES}

Bostrom, R., and Heinen, S. "MIS Problems and Failures: A Socio-Technical Perspective. Part 1: The Causes," MIS Quarterly (1:3), 1978a, pp. 17-32.

Bostrom, R., and Heinen, S. "MIS Problems and Failures: A Socio-Technical Perspective. Part 2: The Application of Socio-Technical Theory," MIS Quarterly (1:4), 1978b, pp. 11-27.

Cummins, R. "Functional Analysis," The Journal of Philosophy (72), 1985, pp. 741-765.

Hempel, C., and Oppenheim, P. "Studies in the Logic of Explanation," Philosophy of Science (15), 1948.

Markus, M. "Toward an Integrated Theory of IT-Related Risk Control," in The Social and Organizational Perspective on Information Technology, R. Baskerville, J. Stage, and J. I. DeGross (eds.), Boston: Kluwer Academic Press, 2000, pp. 167-178.

Monteiro, E. and Hanseth, O. "Social Shaping of Information Infrastructure: On Being Specific About Technology," in Information Technology and Changes in Organizational Work, W. J. Orlikowski, G. Walsham, M. R. Jones, and J. I. DeGross, London: Chapman \& Hall, 1996. 
Morrison, J., and George, J. "Exploring the Software Engineering Component in MIS Research," Communications of the ACM (38:7), 1995, pp. 80-91.

Ngwenyama, O., and Lyytinen, K. "Groupware Environments as Action Constitutive Resources: A Social Action Framework for Analyzing Groupware Technologies," Computer Supported Cooperative Work: The Journal of Collaborative Computing (6:1), 1997, pp. 1-23.

Orlikowski, W. "The Duality of Technology: Rethinking the Concept of Technology in Organizations," Organization Science (3:3), 1992, pp. 398-427.

Orlikowski, W., and Tyre, M. J. "Improvising Organizational Transformation Over Time: A Situated Change Perspective," Information Systems Research (7:1), 1994, pp. 63-92.

Sawyer, S. "The Five Ways to Study Computing: Issues and Examples," The ISI Samuel Lazerow Memorial Lecture, School of Information, University of Washington, December 4, 2000.

Vaishnavi, V. "Panel on Teaching and Promoting Improvement Research Methods in Information Systems and Technology," Ninth Workshop on Information Technologies and Systems, Charlotte, NC, 1999 (available at http://www.cis.gsu.edu/WITS_Improvement_Research/ wits99panel.htm).

van Fraassen, B. C. The Scientific Image, Oxford: Clarendon Press, 1980.

Vidgen, R., and McMaster, T. "Black Boxes and Nonhuman Stake Holders and the Translation of IT through Mediation," in Information Technology and Changes in Organizational Work, W. J. Orlikowski, G. Walsham, M. R. Jones, and J. I. DeGross, London: Chapman \& Hall, 1996.

\section{About the Panelists}

Steve Sawyer is a founding member and an associate professor at the Pennsylvania State University's School of Information Sciences and Technology where he conducts social and organizational informatics research. His current work encompasses the social processes of software development, systems implementation and related organizational change. Steve earned his doctorate at Boston University and has also had the privilege of serving on the faculty of Syracuse University's School of Information Studies. With co-authors Rob Kling, Holly Crawford, Howard Rosenbaum, and Suzie Weisband, his first book, Information Technologies in Human Contexts: Learning from Social and Organizational Informatics, is due out this year. Steve can be reached by e-mail at sawyer@ist.psu.edu.

Steven Haynes recently received his doctorate from the London School of Economics. In his dissertation, he explores explanations in information systems as a product of design rationale. His research interests include systems analysis and design, human-computer interaction, the role of explanation, and other topics in information systems development and management. Steven has taught software engineering, systems development, and inter-organizational information systems. Prior to undertaking his doctoral studies, he worked at Apple Computer, Inc.; Adobe Systems, Inc.; and other technology companies in the United States and Europe. He has held positions as a programmer, systems 
analyst, and application development project manager. He can be reached by email at shaynes@ist.psu.edu.

Duane Truex is interested in the social impacts of information systems development, particularly in the impact on workers and how the emergent properties of organizations may be reflected in emergent ISD approaches. Truex is a member of the editorial board of the Information Systems Journal and is coediting a special issue of The Database for Advances in Information Systems on "Enterprise Resource Planning Systems: A Critical View." He is currently an Associate Professor of CIS at Georgia State University, a Leverhulme Research Fellow in the United Kingdom at the University of Salford, England, and is a visiting Full Research Professor at Aalborg University, Denmark. Duane can be reached by e-mail at dtruex@gsu.edu.

Ojelanki K. Ngwenyama is a Professor of Information Systems and Director of Research and Education in the Center of Excellence in EnterpriseWide Systems Research. He also holds positions as Extraordinary Professor in the Department of Informatics, Faculty of Management Sciences, and Member of the Board of Directors of the School of Information Technology, University of Pretoria; Docent (Research Professor) at University of Jyväskylä, Finland; and Visiting Research Professor at Aalborg University, Denmark (until 2002). Ojelanki was a co-founder of The Collaboratory for Research on Electronic Work (CREW), University of Michigan, Ann Arbor. His research into information systems is informed by critical social theory (CST) and his research papers have been published in a wide range of international journals, including the 1997 MIS Quarterly Best Paper Award (with Allen Lee). Ojelanki serves as a member of the Editorial Board of the Journal of the Association for Information Systems, and Associate Editor of the Journal of Information Technology and People. He has been an active member IFIP WG 8.2 since 1986. Ojelanki can be reached by e-mail at ojelanki@isy.vcu.edu. 